\title{
Kombinasi Pupuk Kandang Sapi, Asam Humat dan Mikoriza Terhadap Infeksi Akar Bermikoriza Tanaman Cabai dan Ketersediaan Unsur Hara Tanah Udipsamments
}

\section{Combination of Cattle Manure, Humic Acid and Mycorrhiza on Mycorrhizal Root Infection in Chili Pepper and Availability of Udipsamments Soil Nutrients}

\author{
M. Zayin Sukri ${ }^{1 *}$, Refa Firgiyanto ${ }^{1}$, Vega Kartika Sari ${ }^{2}$, dan Basuki ${ }^{3}$ \\ ${ }^{1}$ Program Studi Hortikultura Jurusan Produksi Tanaman Politeknik Negeri Jember, \\ ${ }^{2}$ Program Studi Agronomi Fakultas Pertanian Universitas Jember, \\ ${ }^{3}$ Program Studi Ilmu Tanah Fakultas Pertanian Universitas Jember \\ *E-mail : mzayinsukri@ gmail.com
}

\begin{abstract}
This research is an experimental study that aims to examine the combination of cattle manure, humic acid, and mycorrhizae to increase mycorrhizal infections in the roots of chili plants in the Udipsamments soil in Puger District, Jember Regency, which was carried out in May-November 2018. The research design used was a factorial complete randomized block design with 3 factors that were repeated 3 times. The first factor is cattle manure ( 0 tons $/$ ha, 10 tons / ha, 20 tons / ha), the second factor is humic acid (0 ppm / ha, $200 \mathrm{ppm} / \mathrm{ha}$ ), and the third factor is mycorrhiza $(0 \mathrm{~g} /$ plant, $30 \mathrm{~g} /$ plant $)$. The results showed that the combination of cattle manure, humic acid, and mycorrhiza inoculants to chili plant roots was able to increase the root mycorrhizal infection of chili plants and increase the nutrients available in the soil by $191.84 \%$ for nitrogen and $392.93 \%$ for phosphorus.
\end{abstract}

Keywords: cattle manure, humic acid, mycorrhizal infection, soil nutrients

Disubmit : 20 Januari 2019; Diterima: 03 Maret 2019; Disetujui : 10 April 2019

\section{PENDAHULUAN}

Kecamatan Puger merupakan salah satu kecamatan di bagian selatan Kabupaten Jember yang mempunyai luas $148.99 \mathrm{~km}^{2}$ dengan mata pencaharian penduduknya hampir didominasi pertanian terutama tanaman hortikultura. Salah satu komoditas hortikultura yang sering ditanam adalah tanaman cabai. Tanaman cabai merupakan tanaman yang mudah beradaptasi di berbagai jenis tanah, namun dari segi produktifitas terutama kuantitas sangat dipengaruhi oleh karakteristik tanah terutama rizosfer perakaran. Rizosfer terkait dengan karakter fisika, kimia, dan biologi tanah. Karakter fisika berkaitan dengan ketersediaan air, sedangkan karakter kimia dan biologi yang paling berpengaruh yaitu ketersediaan unsur hara bagi tanaman itu sendiri.

Jenis tanah di Kecamatan Puger Kabupaten Jember $30 \%$ didominasi oleh tekstur tanah berpasir. Sukri et al.(2017) menambahkan bahwa hasil analisis tanah dari Kecamatan Puger menunjukkan tekstur tanahnya berpasir, salinitas sangat rendah, KTK rendah, $\mathrm{pH}$ asam hingga netral, $\mathrm{C}$-organik sangat rendah, $\mathrm{N}$ total sangat rendah dan pospat tergolong moderat. Berdasarkan Taksonomi Tanah USDA tergolong jenis tanah Udipsamments. Udipsamments merupakan jenis tanah muda yang berasal dari bahan induk alluvium yang hampir didominasi tekstur berfraksi pasir, sehingga salah satu kendala yang paling utama tekstur tanah berfraksi pasir yaitu ketersediaan unsur hara dan tingkat lengas tanah rendah. Untuk dapat meningkatkan produktifitas tanaman yang ditanam pada jenis tanah tersebut ialah dengan memperbaiki kondisi rizosfer 
perakaran dengan pemberian bahan pembenah tanah. Sebagian bahan pembenah tanah yang mampu memperbaiki kondisi rizosfer yaitu pupuk kandang sapi, asam humat, dan mikoza. Tujuan penelitian ini yaitu mengetahui kombinasi pupuk organik, asam humat, dan mikoriza terhadap tingkat infeksi mikoriza pada perakaran tanaman cabai dan ketersediaan unsur hara di jenis tanah udipsamments Kecamatan Puger Kabupaten Jember.

\section{METODE PENELITIAN}

Penelitian ini merupakan penelitian eksperimen yang dilakukan di rumah kaca Politeknik Negeri Jember di Jember pada bulan Mei-November 2018. Bahan yang digunakan pada penelitian yaitu jenis tanah udipsamments yang diambil di Kecamatan Puger Kabupaten Jember, benih cabai, pupuk kandang, asam humat, inokulum mikoriza, $\mathrm{CO}\left(\mathrm{NH}_{4}\right)_{2}, \mathrm{SP}-36, \mathrm{KCl}$, Insektisida, tali rafia, label, $\mathrm{KOH} 10 \%$, $\mathrm{HCL} 1 \%$, lactofenol blue $0,05 \%$, aguadest, kertas saring. Alat yang digunakan antara lain timbangan analitik, saringan bertingkat (diameter 500, 400, 200, 100, $50 \mu \mathrm{m}$ ), mikroskop perbesaran 100-250 kali, kaca preparat, bunsen, kamera. Rancangan penelitian mengunakan rancangan faktorial dengan 3 faktor yaitu faktor 1 yaitu pupuk kandang ( 0 ton/ha, 10 ton/ha, 20 ton/ha), faktor ke-2 yaitu asam humat ( 0 ppm/ha, $200 \mathrm{ppm} / \mathrm{ha})$, dan faktor ke-3 yaitu mikoriza (0 g/tanaman, $30 \mathrm{~g} / \mathrm{tanaman})$ sehingga didapat kombinasi perlakuan sebanyak 12 perlakuan (Tabel 1.) dan tiap perlakuan diulang sebanyak 3 kali.

Tabel 1. Kombinasi Perlakuan

\begin{tabular}{|c|c|c|}
\hline No. & Kode & Perlakuan \\
\hline 1 & P0 A0 M0 & Pupuk kandang 0 ton $/$ ha + Asam humat $0 \mathrm{ppm}+$ Mikoriza $0 \mathrm{~g} /$ tanaman \\
\hline 2 & P0 A0 M1 & Pupuk kandang 0 ton $/$ ha + Asam humat $0 \mathrm{ppm}+$ Mikoriza $30 \mathrm{~g} /$ tanaman \\
\hline 3 & P0 A1 M0 & Pupuk kandang 0 ton / ha + Asam humat $200 \mathrm{ppm}+$ Mikoriza $0 \mathrm{~g} /$ tanaman \\
\hline 4 & P0 A1 M1 & Pupuk kandang 0 ton $/$ ha + Asam humat $200 \mathrm{ppm}+$ Mikoriza $30 \mathrm{~g} /$ tanaman \\
\hline 5 & P1 A0 M0 & Pupuk kandang 10 ton $/$ ha + Asam humat $0 \mathrm{ppm}+$ Mikoriza $0 \mathrm{~g} /$ tanaman \\
\hline 6 & P1 A0 M1 & Pupuk kandang 10 ton $/$ ha + Asam humat $0 \mathrm{ppm}+$ Mikoriza $30 \mathrm{~g} /$ tanaman \\
\hline 7 & P1 A1 M0 & Pupuk kandang 10 ton / ha + Asam humat $200 \mathrm{ppm}+$ Mikoriza $0 \mathrm{~g} /$ tanaman \\
\hline 8 & P1 A1 M1 & Pupuk kandang 10 ton / ha + Asam humat $200 \mathrm{ppm}+$ Mikoriza $30 \mathrm{~g} /$ tanaman \\
\hline 9 & $\mathrm{P} 2 \mathrm{~A} 0 \mathrm{M} 0$ & Pupuk kandang 20 ton $/$ ha + Asam humat $0 \mathrm{ppm}+$ Mikoriza $0 \mathrm{~g} /$ tanaman \\
\hline 10 & $\mathrm{P} 2 \mathrm{~A} 0 \mathrm{M} 1$ & Pupuk kandang 20 ton / ha + Asam humat $0 \mathrm{ppm}+$ Mikoriza $30 \mathrm{~g} /$ tanaman \\
\hline 11 & P2 A1 M0 & Pupuk kandang 20 ton / ha + Asam humat 200 ppm + Mikoriza 0 g / tanaman \\
\hline 12 & P2 A1 M1 & Pupuk kandang 20 ton / ha + Asam humat 200 ppm + Mikoriza $30 \mathrm{~g} /$ tanaman \\
\hline
\end{tabular}

Parameter penelitian meliputi parameter kualitatif meliputi infeksi mikoriza di perakaran tanaman dengan metode pengecatan pewarnaan akar; unsur hara tanah meliputi unsur hara nitrogen $(\mathrm{N})$ dengan metode kjeldahl, unsur hara pospor $\left(\mathrm{P}_{2} \mathrm{O}_{5}\right)$ dengan metode olsen.

\section{HASIL DAN PEMBAHASAN}

Hasil analisis laboratorium menunjukkan terdapat interaksi penggunaan bahan pembenah tanah terhadap peubah spora dalam tanah dan infeksi akar mikoriza yang terdapat pada rizosfer perakaran sebagai mana tampak pada Gambar 1, dan Gambar 2. Identifikasi spora mikoriza diperoleh dengan menggunakan metode penyaringan bertingkat, Hasil identifikasi spora mikrorisa yang berkembang di semua perlakuan, jenis spora yang ditemukan yaitu bergenus Acouluspora sedangkan Spesies Acouluspora dalam kategori Acouluspora capsicula dengan ukuran diameter rata-rata $279 \mu \mathrm{m}$. Tampak pada Gambar 1. warna didominasi dengan warna kuning sampai kuning tua dengan beberapa spora yang berakar, dimana menunjukkan spora yang ada sebagian sudah tua dan akan bereproduksi. 


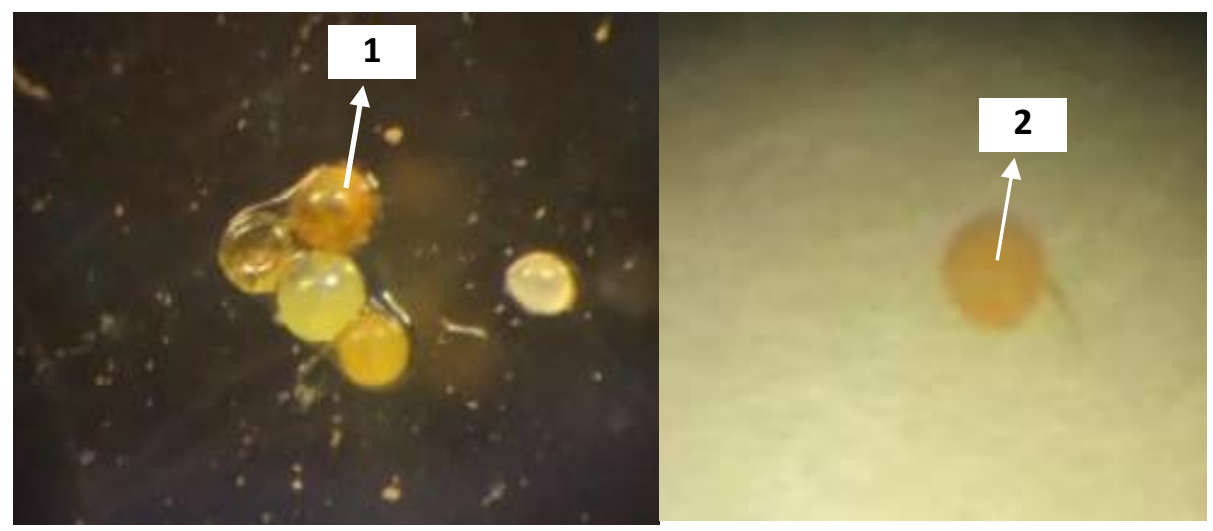

Gambar 1. Spora mikoriza spesies Acouluspora capsicula dan Saccule

Identifikasi infeksi akar pada tanaman oleh mikoriza menunjukkan terdapat aktifitas mikoriza yang merespon terhadap tanaman inang. Respon tersebut dapat berbeda-beda tergantung dari sifat kekebalan dari tanaman inang terhadap benda lain disekitarnya. Infeksi mikoriza pada akar tanaman cabai ditunjukkan pada Gambar 2. Pada Gambar tersebut, terdapat perlakuan yang terinfeksi hanya arbuskular saja, tetapi terdapat juga perlakuan yang terifeksi mikoriza secara lengkap meliputi spora, hifa, dan arbuskular. Menurut Parapasan \& Gusta (2017), waktu perkecambahan dan pertumbuhan spora, akar terinfeksi dan hifa diduga tidak bersamaan. Lebih lanjut Wirawan (2014) mengungkapkan proses terbentuknya struktur-struktur tersebut bahwa perkembangan kolonisasi CMA (Cendawan Mikoriza Arbuskular) dimulai pembentukan apresorium pada permukaan akar oleh hifa eksternal yang berasal dari spora yang berkecambah. Apresorium masuk kedalam akar melalui celah epidermis, kemudian membentuk hifa intraselular disepanjang epidermis akar, dan selanjutnya arbuskular dan vesicular terbentuk. Aktifitas mikoriza dalam menginfeksi akar tanaman setelah dianalisis ditemukan berwarna biru berbentuk bulat yang disebabkan karena struktur tersebut menyerap lactofenol blue.Sukmawaty et al. (2018) mengungkapkan, terlihatnya struktur vesicular dan arbuskular menandakan telah terjadi infeksi atau kolonisasi simbiosis antara akar tanaman dengan CMA. Infeksi CMA dalam akar pada perlakuan terlihat pada Tabel 2.

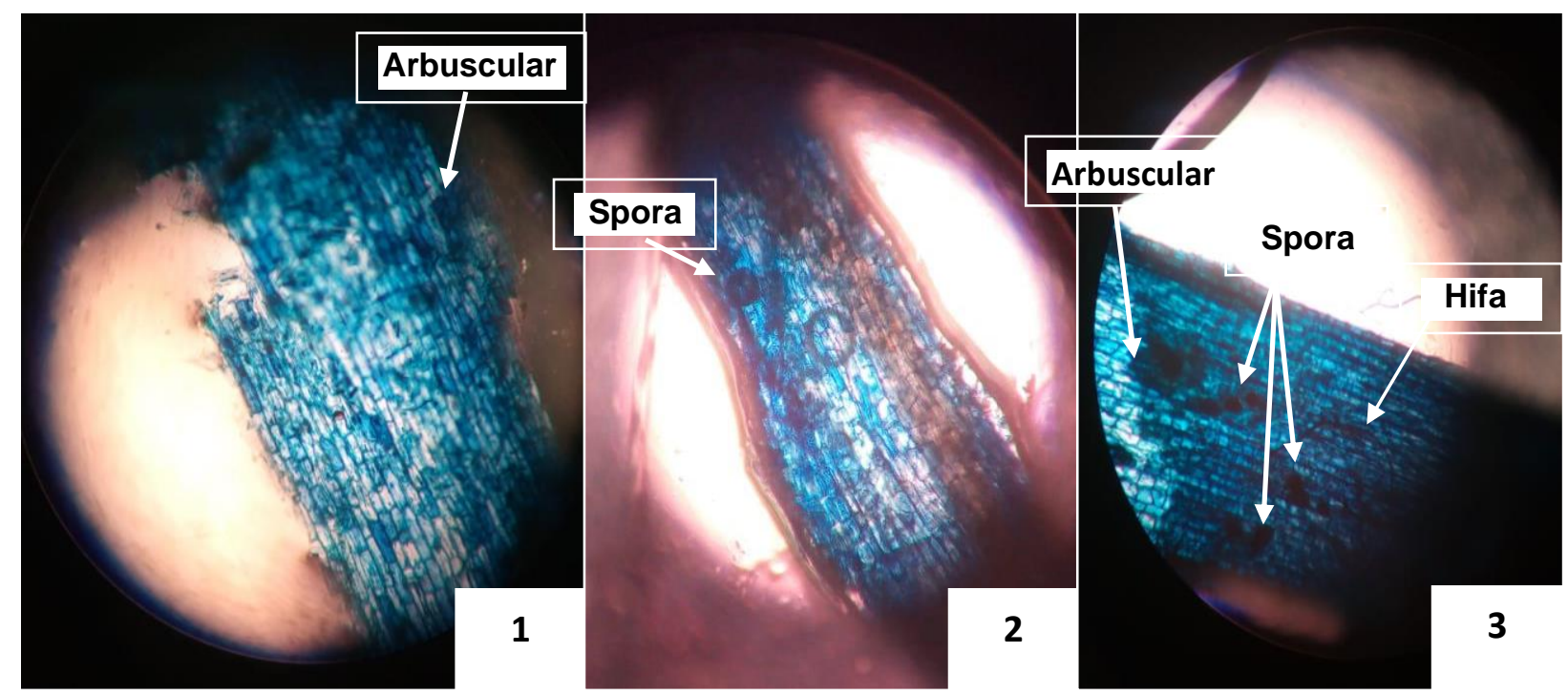

Gambar 2. Struktur VAM dalam akar tanaman cabai melalui metode pengecatan dan pewarnaan akar (1. Perlakuan Pupuk kandang 20 ton/ha + Asam humat 200 ppm + Mikoriza 30 g/tanaman 2. Perlakuan Pupuk kandang 20 ton / ha + Asam humat 200 ppm + Mikoriza 0 g / tanaman, 3. Perlakuan Pupuk kandang 20 ton/ha + Asam humat 200 ppm + Mikoriza 30 g/tanaman). 
Tabel 2 menunjukkan bahwa semua kombinasi perlakuan kecuali kontrol dengan perlakuan Pupuk kandang 0 ton/ha + Asam humat 0 ppm + Mikoriza 0 g/tanaman menunjukkan adanya infeksi CMA dengan intensitas yang berbeda. Intensitas infeksi CMA dipengaruhi oleh berbagai faktor salah satunya ialah pemupukan (Sukmawaty et al., 2018).

Tabel 2. Keberadaan spora di dalam tanah, infeksi CMA di akar, unsur hara di tanah pasca panen

\begin{tabular}{|c|c|c|c|c|c|c|c|c|c|}
\hline \multirow[t]{2}{*}{ No. } & \multirow[t]{2}{*}{ Perlakuan } & \multicolumn{4}{|c|}{ Infeksi VAM di akar } & \multicolumn{4}{|c|}{ Unsur Hara di Tanah } \\
\hline & & Vesikel & Arbuskular & Spora & Hifa & $\begin{array}{c}\mathrm{N} \\
(\%)\end{array}$ & $\begin{array}{c}\% \text { dari } \\
\text { P0A0M0 }\end{array}$ & $\begin{array}{r}\mathrm{P}_{2} \mathrm{O}_{5} \\
(\mathrm{ppm})\end{array}$ & $\begin{array}{c}\% \text { dari } \\
\text { P0A0M } \\
0\end{array}$ \\
\hline 1 & P0A0M0 & - & - & - & - & 0.049 & 0.00 & 13.30 & 0.00 \\
\hline 2 & P0A1M0 & - & V & - & - & 0.064 & 30.61 & 36.13 & 171.65 \\
\hline 3 & P0A0M1 & V & - & - & - & 0.129 & 163.27 & 19.99 & 50.30 \\
\hline 4 & P0A1M1 & - & V & - & - & 0.121 & 146.94 & 44.95 & 237.97 \\
\hline 5 & P1A0M0 & - & V & - & - & 0.095 & 93.88 & 22.44 & 68.72 \\
\hline 6 & P1A1M0 & - & V & - & - & 0.143 & 191.84 & 40.26 & 202.71 \\
\hline 7 & P1A0M1 & - & V & - & - & 0.119 & 142.86 & 40.70 & 206.02 \\
\hline 8 & P1A1M1 & - & V & - & - & 0.092 & 87.76 & 22.23 & 67.14 \\
\hline 9 & P2A0M0 & - & V & - & - & 0.055 & 12.24 & 35.83 & 169.40 \\
\hline 10 & P2A1M0 & - & - & V & - & 0.113 & 130.61 & 65.56 & 392.93 \\
\hline 11 & P2A0M1 & - & V & - & V & 0.124 & 153.06 & 42.81 & 221.88 \\
\hline 12 & P2A1M1 & V & V & V & V & 0.122 & 148.98 & 52.03 & 291.20 \\
\hline
\end{tabular}

Tabel 2 juga menunjukkan pengaruh kombinasi dari penggunaan pupuk organik, asam humat, dan inokulan mikoriza terhadap peningkatan ketersediaan unsur hara dalam tanah. Peningkatan terendah pada perlakuan Pupuk kandang 20 ton / ha + Asam humat 0 ppm + Mikoriza 0 g/tanaman (12.24 \%) dan tertinggi pada perlakuan Pupuk kandang 10 ton/ha + Asam humat 200 ppm + Mikoriza 0 g/tanaman (191.84 \%) pada unsur hara nitrogen, sedangkan terhadap ketersediaan unsur hara pospat, perlakuan dengan peningkatan terendah terdapat pada perlakuan Pupuk kandang 0 ton/ha + Asam humat $0 \mathrm{ppm}+$ Mikoriza $30 \mathrm{~g} /$ tanaman (50.30\%) dan tertinggi pada perlakuan Pupuk kandang 20 ton/ha + Asam humat $200 \mathrm{ppm}+$ Mikoriza 0 g/tanaman dengan presentase 392,93\% bila dibandingkan kontrol Pupuk kandang 0 ton/ha + Asam humat 0 ppm + Mikoriza $0 \mathrm{~g} /$ tanaman. Hal tersebut menunjukkan penggunaan bahan organik dan asam humat dapat meningkatkan ketersediaan unsur hara nitrogen dan pospat. Salah satu jenis pupuk organik penyedia unsure hara yaitu pupuk kandang sapi. Pupuk kandang sapi menyediakan unsur hara makro dan mikro, namun kelemahan pupuk kandang ialah pengaruhnya terhadap peningkatan kesuburan tanah lambat dan harus diberikan dalam jumlah besar (Kusuma et al., 2017), sehingga dalam aplikasinya perlu ditambahkan asam humat (Sukri et al., 2017). Menurut (Hermanto et al., 2013), asam humat berperan dalam meningkatkan ketersediaan nitrogen dan efisiensi pemupukan $\mathrm{N}$ melalui perlambatan pelepasan nitrogen menjadi nitrat (nitrifikasi) sehingga tanaman dapat menyerap nitrogen lebih banyak. Pengaruh asam humat dengan ketersediaan P, (Wahyuningsih et al., 2017) mengungkapkan bahwa ketersediaan P dapat ditingkatkan dengan pemberian bahan organik karena selama proses dekomposisi bahan organik akan dihasilkan asam humat. Asam humat memegang peranan penting pada lepasnya pengikatan $\mathrm{Al}$ dan $\mathrm{Fe}$, sehingga $\mathrm{P}$ menjadi tersedia. Sejalan dengan Victolika et al. (2014), peningkatan kesuburan tanah baik secara fisik, kimia, maupun biologi tanah merupakan pengaruh tidak langsung dari asam humat sedangkan pengaruh secara langsung yaitu memperbaiki proses metabolism didalam tanaman. Dalam hal ini, perlakuan yang menggunakan mikoriza bukan termasuk perlakuan yang meningkatkan ketersediaan unsur hara tertinggi karena diduga mikoriza masih dalam proses pembentukan di dalam akar tanaman. Menurut Nurhayati (2012), kompatibilitas mikoriza dengan tanaman inang sangat bervariasi tergantung pada spesies mikoriza, jenis tanaman inang dan kondisi lingkungan. Faktor lingkungan tanah yang mempengaruhi CMA terutama ialah bahan organik dan residu akar, unsur hara, $\mathrm{pH}$, suhu, serta kadar air tanah. 


\section{KESIMPULAN}

Kombinasi bahan organik, asam humat, dan inokulan mikoriza terhadap perakaran tanaman cabai mampu meningkatkan infeksi mikoriza perakaran tanaman cabai serta kombinasi pupuk kandang dan asam humat dapat meningkatkan unsur hara tersedia di dalam tanah sebesar $191.84 \%$ untuk unsur hara nitrogen dan $291.20 \%$ untuk unsur hara pospat.

\section{DAFTAR PUSTAKA}

Hermanto, D., Dharmayani, N.K.T., Kurnianingsih, R. \& Kamali, S.. 2013. Pengaruh Asam Humat Sebagai Pelengkap Pupuk Terhadap Ketersediaan dan Pengambilan Nutrien pada Tanaman Jagung di Lahan Kering Kec.Bayan-NTB. Ilmu Pertanian, 16(2): 28-41.

Kusuma, A.., Rosniawaty, S. \& Maxiselly, Y. 2017. Pengaruh Asam Humat dan Pupuk Kandang Sapi Terhadap Pertumbuhan Tanaman Kakao Belum Menghasilkan Klon Sulawei. J. Kultivasi, 1: 793799.

Nurhayati 2012. Infektivitas Mikoriza Pada Berbagai Jenis Tanaman Inang dan Beberapa jenis Sumber Inokulum. J. Floratek, 7: 25-31.

Parapasan, Y. \& Gusta, A.R. 2017. Waktu dan Cara Aplikasi Cendawan Mikoriza Arbuskular (CMA) pada Pertumbuhan Bibit Tanaman Kopi. Jurnal Penelitian Pertanian Terapan.

Sukmawaty, E., Hafsan, H. \& Asriani, A. 2018. Identifikasi Cendawan Mikoriza Arbuskula Dari Perakaran Tanaman Pertanian. Biogenesis: Jurnal Ilmiah Biologi.

Sukri, M.Z., Sari, V.K. \& Firgiyanto, R. 2017. Improving Soil Fertilizer Through Application of Organic Fertilizer Humid Acid and Mikoriza in Supporting Growth and Production of Chilli Plants In Sand Land. IOP Conf. Ser.: Earth Environ. Sci.

Victolika, H., Sarno \& Ginting, Y.. 2014. Pengaruh Pemberian Asama Humat dan K Terhadap Pertumbuhan dan Produksi Tanaman Tomat (Lycopersicum esculentum Mill). J. Agotek Tropika (2), 2: 297-301.

Wahyuningsih, W., Proklamasiningsih, E. \& Dwiati, M. 2017. Serapan Fosfor dan Pertumbuhan Kedelai(Glycine max) pada Tanah Ultisol dengan Pemberian Asam Humat. Biosfera.

Wirawan, G. 2014. Identifikasi Fungi Mikoriza Arbuskular Secara Mikroskopis pada Rhizosfer Tanaman Alang-Alang. Universitas Udayana. 